\title{
The velocity distribution of periodic comets and the meteor shower on Mars
}

\author{
Yuehua $\mathrm{Ma}^{1,2,3}$, I. P. Williams ${ }^{2}$, W. H. Ip ${ }^{3}$, and Wenping Chen ${ }^{3}$ \\ ${ }^{1}$ Purple Mountain Observatory, Academia Sinica, Nanjing 210008, PR China; National Astronomical Observatories, \\ Academia Sinica, PR China \\ 2 Astronomy Unit, Queen Mary, London E1 4NS, UK \\ 3 Institute of Astronomy, National Central University, Taiwan 32054, PR China
}

Received 10 September 2001 / Accepted 29 July 2002

\begin{abstract}
The collision velocities with Mars of the known periodic comets with perihelion distances less than the orbital radius of Mars $1.52 \mathrm{au}$ are calculated and statistically analyzed. The velocity distribution shows that short-period comets usually have smaller collision velocities than the long-period comets whether they are numbered or unnumbered. For comets with period $P \leq 270 \mathrm{y}$, most collision velocities with Mars are less than $30 \mathrm{~km} \mathrm{~s}^{-1}$. These velocities are smaller than the corresponding collision velocities with Earth. Based on the similarity of the velocity distributions of the comets and meteoroid streams, meteor showers on Mars are discussed briefly.
\end{abstract}

Key words. celestial mechanics - comets: general - meteors, meteoroids

\section{Introduction}

It is well known that comets, as they near the perihelion of their orbits, release large numbers of dust grains (Kirkwood 1861) due to the normal process of gas ejection. These particles, namely meteoroids, leave the cometary nucleus at speeds which are significantly less than the orbital velocity of the comet (Whipple 1951). In consequence, these meteoroids move on almost the same orbits as the parent comets, gradually drifting ahead and behind the comet because of small differences in orbital period. After a time interval of a few tens of cometary periods, the meteoroids will have spread all the way around the cometary orbit (Steel 1994; Williams 1996). At this stage, meteors (which are produced by the impact of the stream meteoroids with the atmosphere of the Earth) can be observed whenever the Earth passes through the cometary nodes. In principle, there could also be meteor showers on Mars or any other planets with an atmosphere whenever the planet encounters a meteoroid streams.

Meteoroids strike the Earth with a velocity that is similar to the orbital velocity, that is, several tens of kilometers per second. At such velocities, dust impacts can affect all phases of spacecraft operation (Beech et al. 1995, 1997; McBride 1997; McBride \& McDonnell 1999). For example, the Mir-1 solar panels were damaged on the night of the Perseid meteor shower maximum (Lenorovitz 1993). The ESA Olympus communications satellite may have been disabled by a Perseid meteoroid (Caswell et al. 1995). As Mars exploration is entering its

Send offprint requests to: Yuehua Ma,

e-mail: yhma@mail.pmo.ac.cn second era, Mars-orbiting spacecraft and ground operations, both manned and unmanned, are similarly vulnerable to meteoroid impact. In addition to this potential danger, meteor shower on Mars are of scientific interest. Mars may be an ideal vantage point to view meteors, with emphasis on determining the compositions and structures of meteoroids and comets with perihelia beyond Earth's orbit (Adolfsson et al. 1996; Christou \& Beurle 1999; Treiman \& Treiman 2000). The undertaking of missions to Mars brings an opportunity to extend our knowledge of the meteoroid stream complex to a wide range of the heliocentric distances.

As the meteoroid stream orbit and the orbit of the parent comet are very similar, the velocities of both at one astronomical unit should be very similar. Unfortunately, most comets do not produce meteoroid streams that can be intersected by the Earth while many of the minor meteor showers do not have an identified parent comet. For this reason, Hughes \& Williams (2000) have investigated the velocity distributions of comets and meteor streams, and found these to be very similar. They found that the velocities of short-period comets at Earth are generally small. As the distributions were similar, they concluded that the meteor population did mainly come from the short period comets. Most comets do not of course collide with Mars, nor indeed with the Earth. In this paper, we calculate the velocity that periodic comets would have on impact with Mars having adjusted the argument of perihelion so as to make such a collision possible. We investigate the distribution of these velocities and briefly discuss the implications for meteor showers on Mars. 


\section{Comet-Mars collision velocity}

As already mentioned, we are going to adjust the argument of perihelion, $\omega$, of cometary orbits so that the heliocentric distance of the node, $r_{\mathrm{N}}$, is equal to $1.52 \mathrm{au}$. Clearly one can only do this for those comets whose perihelion distance is less than $1.52 \mathrm{au}$, and whose aphelion distance is greater than this value. Hence we search through the catalogue given in Marsden \& Williams (1996) and select all comets that satisfy the above. For each selected orbit, the change in $\omega$ required to make the nodal distance $1.52 \mathrm{au}$ is then calculated and a new orbit is defined with the correct value of $\omega$. In reality, changes in the argument of the perihelion can introduce secular changes in the orbital inclination and the eccentricity. We shall ignore this since it is hard to calculate and is unlikely to alter the distribution of velocities, though of course changing individual values.

Assuming Mars moves in the ecliptic plane and its orbit is circular, the comet-Mars collision velocity $V$ is given as (Hughes \& Williams 2000)

$$
\begin{aligned}
V^{2} & =G M_{\odot}\left[\frac{3}{r_{\mathrm{m}}}-2 \cos i\left(\frac{p}{r_{\mathrm{m}}^{3}}\right)^{0.5}-\frac{1}{a}\right] \\
& =\frac{G M_{\odot}}{r_{\mathrm{m}}}\left[3-2\left(\frac{q(1+e)}{r_{\mathrm{m}}}\right)^{0.5} \cos i-\frac{r_{\mathrm{m}}}{q}(1-e)\right],
\end{aligned}
$$

where $G$ is the constant of gravitation, $M_{\odot}$ is the mass of the Sun and $r_{\mathrm{m}}$ is the heliocentric distance of Mars. $i, p, e, a$ and $q$ are the inclination, semi-parameter, eccentricity, semi-major axis and perihelion distance of the cometary orbit, respectively.

In fact, the orbit of Mars has an eccentricity of 0.0934 and an inclination of 1.85 . Any resultant small changes in the values of individual impact velocities do not affect the distribution of these velocities in a systematic fashion (Babadzhanov \& Obrubov 1992) and so we shall not correct for this.

As $G=6.6726 \times 10^{-11} \mathrm{Nm}^{2} \mathrm{~kg}^{-2}, M_{\odot}=1.9891 \times 10^{30} \mathrm{~kg}$ and $r_{\mathrm{m}}=1.52 \mathrm{au}=1.52 \times 1.4960 \times 10^{11} \mathrm{~m}$, Eq. (1) becomes

$$
V^{2}=582.24\left[3-2\left(\frac{q(1+e)}{r_{\mathrm{m}}}\right)^{0.5} \cos i-\frac{r_{\mathrm{m}}}{q}(1-e)\right] \mathrm{km}^{2} \mathrm{~s}^{-2} \text {. }
$$

In order to calculate the true impact speed with Mars, $V_{i}$, the effect of the gravitational field of Mars has to be taken into account. Hence, a term of $2 G M_{\mathrm{m}} / R_{\mathrm{m}}=25.28 \mathrm{~km}^{2} \mathrm{~s}^{-2}$ is added to Eq. (2), where $M_{\mathrm{m}}$ and $R_{\mathrm{m}}$ are the mass and radius of Mars, respectively, giving the true comet-Mars impact velocity $V_{i}$ as

$$
\begin{aligned}
V_{i}^{2}= & 25.28+582.24\left[3-2\left(\frac{q(1+e)}{r_{\mathrm{m}}}\right)^{0.5} \cos i\right. \\
& \left.-\frac{r_{\mathrm{m}}}{q}(1-e)\right] \mathrm{km}^{2} \mathrm{~s}^{-2} .
\end{aligned}
$$

Using Eq. (3), we calculate the comets-Mars impact velocities of all comets within the correct perihelion and aphelion range that have data given in Marsden \& Williams (1996). In Table 1 we give the results for all numbered periodic comets that have more than one recorded perihelion passage and where the perihelion distance is less than $1.52 \mathrm{au}$.
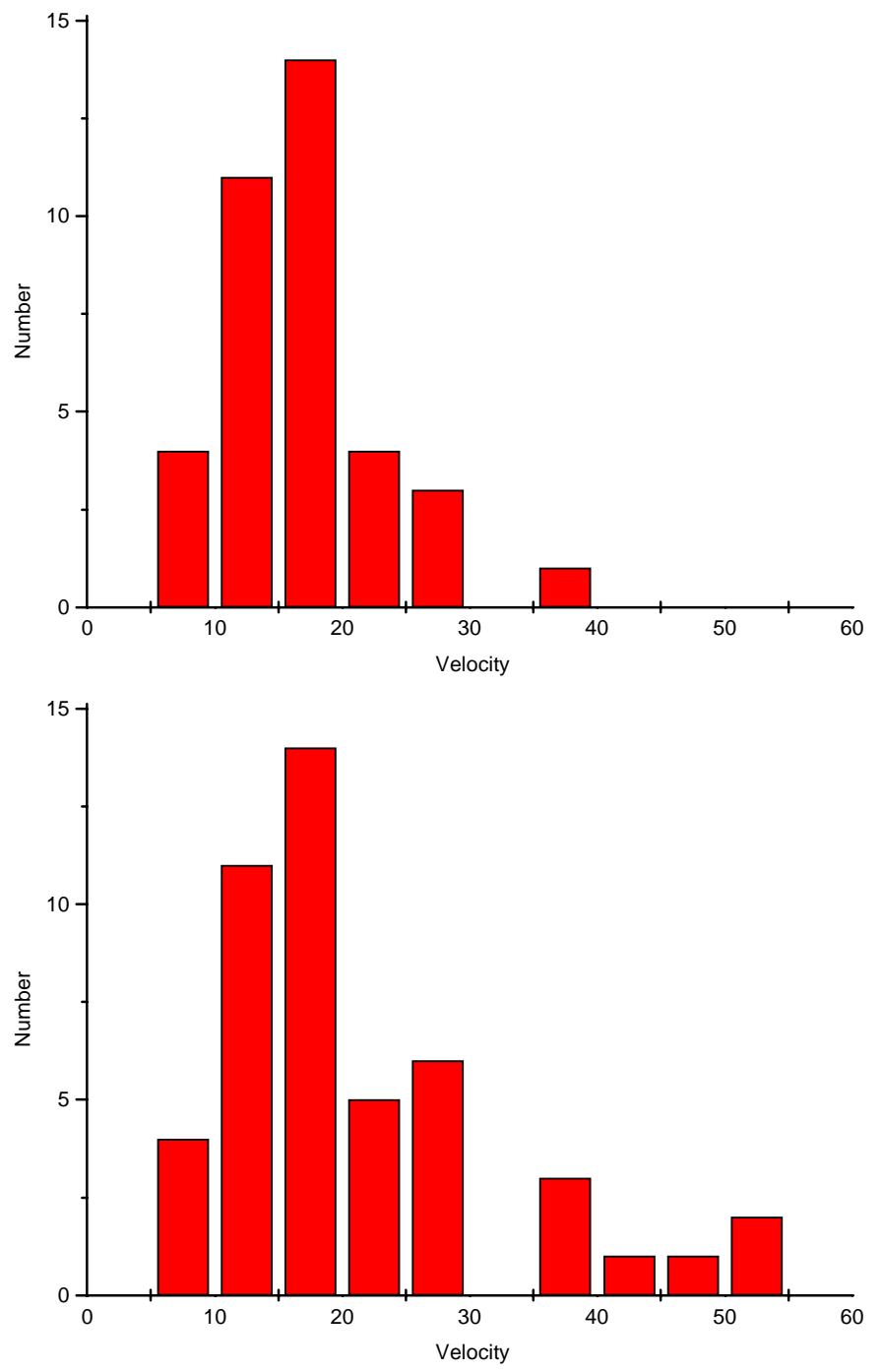

Fig. 1. The upper histogram is the distribution of impact velocities of the 37 numbered periodic comets given in Table 1 that have $P<20 \mathrm{y}$. The lower histogram is the distribution of impact velocities of all the 47 numbered periodic comets given in Table 1 .

In Table 2 the results are given for the unnumbered periodic comets similarly selected. In addition, 6 comets are included (and denoted with the symbol "*”) that have been discovered since 1996 and the data for these are taken from Minor Planet Center (MPC) web site.

Inspection of Table 1 shows that the impact velocities of most of the short-period comets are smaller than those of the long-period comets. The mean impact velocity of the 37 comets with a period less than $20 \mathrm{y}$ is $16.70 \mathrm{~km} \mathrm{~s}^{-1}$ while the median impact velocity is $15.86 \mathrm{~km} \mathrm{~s}^{-1}$. The corresponding mean value for all the comets in Table 1 is $21.07 \mathrm{~km} \mathrm{~s}^{-1}$ while the median impact velocity is $17.31 \mathrm{~km} \mathrm{~s}^{-1}$. All these values are smaller than the corresponding values on Earth as found by Hughes \& Williams (2000), and is not unexpected as the Keplerian velocity decreases with heliocentric distance.

Figure 1 shows two histograms of the number of comets as a function of impact velocity. The lower histogram is for all the comets given in Table 1, while the upper histogram is for the sub-set of comets in Table 1 that have a period less 
Table 1. The calculated impact velocities, $V_{i}$, between Mars and those numbered periodic comets given in Marsden \& Williams (1996) which have perihelion distance $q<1.52$ au and have been observed at more than one apparition. The orbital inclinations and eccentricities are denoted by $i$ and $e . V$ is the velocity before adding the contribution from the acceleration due to the gravitational field of Mars.

\begin{tabular}{|c|c|c|c|c|c|c|}
\hline $\begin{array}{l}\text { comet } \\
\text { name }\end{array}$ & $\begin{array}{l}\text { Period } \\
\text { (y) }\end{array}$ & $\begin{array}{c}q \\
(\mathrm{au})\end{array}$ & $e$ & $\begin{array}{c}i \\
(\mathrm{deg})\end{array}$ & $\begin{array}{c}V \\
\mathrm{~km} \mathrm{~s}^{-1}\end{array}$ & $\begin{array}{c}V_{i} \\
\mathrm{~km} \mathrm{~s}^{-1}\end{array}$ \\
\hline $2 \mathrm{P}$ & 3.28 & 0.331396 & 0.850013 & 11.92940 & 24.95 & 25.45 \\
\hline $107 \mathrm{P}$ & 4.30 & 1.000483 & 0.621670 & 2.78298 & 14.53 & 15.37 \\
\hline $26 \mathrm{P}$ & 5.11 & 0.996811 & 0.663805 & 21.08677 & 17.72 & 18.42 \\
\hline $79 \mathrm{P}$ & 5.21 & 1.200685 & 0.600768 & 2.93945 & 12.07 & 13.07 \\
\hline $141 \mathrm{P}$ & 5.22 & 0.748904 & 0.751085 & 12.81261 & 19.96 & 20.58 \\
\hline $96 \mathrm{P}$ & 5.24 & 0.124718 & 0.958636 & 60.07425 & 34.93 & 35.29 \\
\hline $45 \mathrm{P}$ & 5.27 & 0.532052 & 0.824241 & 4.24838 & 22.95 & 23.49 \\
\hline $25 \mathrm{D}$ & 5.43 & 1.270041 & 0.586849 & 5.36573 & 7.93 & 9.39 \\
\hline $73 \mathrm{P}$ & 5.43 & 0.932772 & 0.694815 & 11.42359 & 17.14 & 17.86 \\
\hline $5 \mathrm{D}$ & 5.46 & 0.589847 & 0.809796 & 29.3821 & 24.73 & 25.23 \\
\hline $41 \mathrm{P}$ & 5.46 & 1.065309 & 0.656365 & 9.22518 & 14.96 & 15.78 \\
\hline $46 \mathrm{P}$ & 5.46 & 1.063764 & 0.656748 & 11.72252 & 15.30 & 16.10 \\
\hline $124 \mathrm{P}$ & 5.46 & 1.412895 & 0.554250 & 31.47086 & 16.57 & 17.31 \\
\hline $10 \mathrm{P}$ & 5.47 & 1.481680 & 0.522817 & 11.97670 & 8.65 & 10.00 \\
\hline $9 \mathrm{P}$ & 5.50 & 1.500048 & 0.518953 & 10.54134 & 7.89 & 9.36 \\
\hline $88 \mathrm{P}$ & 5.57 & 1.406129 & 0.552672 & 4.39838 & 8.64 & 10.00 \\
\hline $37 \mathrm{P}$ & 6.13 & 1.446019 & 0.568121 & 7.16277 & 8.50 & 9.88 \\
\hline $104 \mathrm{P}$ & 6.18 & 1.396623 & 0.585207 & 15.48913 & 11.43 & 12.49 \\
\hline $7 \mathrm{P}$ & 6.31 & 1.255891 & 0.634425 & 22.30141 & 15.43 & 16.23 \\
\hline $103 \mathrm{P}$ & 6.39 & 1.031722 & 0.700375 & 13.61887 & 16.57 & 17.32 \\
\hline $6 \mathrm{P}$ & 6.51 & 1.345814 & 0.614046 & 19.52380 & 13.49 & 14.40 \\
\hline $67 \mathrm{P}$ & 6.59 & 1.300033 & 0.630193 & 7.11331 & 11.47 & 12.52 \\
\hline $21 \mathrm{P}$ & 6.61 & 1.033732 & 0.706472 & 31.85878 & 20.75 & 21.35 \\
\hline $49 \mathrm{P}$ & 6.61 & 1.368590 & 0.611541 & 18.29066 & 12.83 & 13.78 \\
\hline $3 \mathrm{D}$ & 6.62 & 0.860265 & 0.755879 & 12.5500 & 19.06 & 19.71 \\
\hline $62 \mathrm{P}$ & 6.64 & 1.495854 & 0.576610 & 10.49530 & 8.51 & 9.88 \\
\hline $112 \mathrm{P}$ & 6.64 & 1.457862 & 0.587773 & 24.20476 & 13.67 & 14.57 \\
\hline $15 \mathrm{P}$ & 6.67 & 1.035557 & 0.710304 & 3.67366 & 15.67 & 16.46 \\
\hline $18 \mathrm{P}$ & 6.72 & 1.292928 & 0.638584 & 17.83226 & 13.84 & 14.72 \\
\hline $19 \mathrm{P}$ & 6.88 & 1.365123 & 0.622803 & 30.27070 & 17.00 & 17.73 \\
\hline $24 \mathrm{P}$ & 8.22 & 1.205005 & 0.704809 & 11.75148 & 14.34 & 15.20 \\
\hline $58 \mathrm{P}$ & 8.24 & 1.381169 & 0.661426 & 13.47858 & 11.81 & 12.84 \\
\hline $72 \mathrm{P}$ & 9.01 & 0.790200 & 0.817792 & 9.12682 & 20.64 & 21.24 \\
\hline $64 \mathrm{P}$ & 9.21 & 1.338894 & 0.694590 & 8.43693 & 11.78 & 12.81 \\
\hline $85 \mathrm{P}$ & 11.23 & 1.158161 & 0.774364 & 4.87674 & 15.05 & 15.87 \\
\hline $8 \mathrm{P}$ & 13.51 & 0.997734 & 0.824088 & 54.69256 & 29.24 & 29.67 \\
\hline $66 \mathrm{P}$ & 14.97 & 1.274280 & 0.787683 & 18.70094 & 15.82 & 16.60 \\
\hline $27 \mathrm{P}$ & 27.41 & 0.747872 & 0.918742 & 28.95677 & 25.72 & 26.21 \\
\hline $55 \mathrm{P}$ & 33.22 & 0.976585 & 0.905504 & 162.48615 & 53.74 & 53.97 \\
\hline $20 \mathrm{D}$ & 61.86 & 1.254043 & 0.919829 & 40.88769 & 24.15 & 24.67 \\
\hline $13 \mathrm{P}$ & 69.56 & 1.175501 & 0.930295 & 44.66567 & 26.14 & 26.62 \\
\hline $23 \mathrm{P}$ & 70.54 & 0.478751 & 0.971952 & 19.33387 & 28.81 & 29.25 \\
\hline $12 \mathrm{P}$ & 70.92 & 0.780779 & 0.954604 & 74.19157 & 36.06 & 36.41 \\
\hline $122 \mathrm{P}$ & 74.36 & 0.658892 & 0.962738 & 85.39111 & 40.13 & 40.44 \\
\hline $1 \mathrm{P}$ & 76.00 & 0.587104 & 0.967277 & 162.24220 & 51.60 & 51.84 \\
\hline $109 \mathrm{P}$ & 135.0 & 0.958217 & 0.963589 & 113.42664 & 47.20 & 47.47 \\
\hline $35 \mathrm{P}$ & 154.9 & 0.748490 & 0.974050 & 64.20652 & 34.89 & 35.25 \\
\hline
\end{tabular}

than 20 years. It can be seen that the impact velocities of the short-period comets $(P<20 \mathrm{y})$ are less than $30 \mathrm{~km} \mathrm{~s}^{-1}$ and most lie between 10 and $20 \mathrm{~km} \mathrm{~s}^{-1}$. The impact velocities of all the comets with $P>20 \mathrm{y}$ (the Halley-family comets) are larger than $20 \mathrm{~km} \mathrm{~s}^{-1}$. In fact the velocities all lie in the range $24.67 \mathrm{~km} \mathrm{~s}^{-1} \leq V_{i} \leq 53.98 \mathrm{~km} \mathrm{~s}^{-1}$.

The velocity distribution of the unnumbered comets given in Table 2 shows the same characteristic as the numbered 
Table 2. The calculated impact velocities, $V_{i}$, between Mars and those un-numbered periodic comets given in Marsden \& Williams (1996) which have perihelion distance $q<1.52$ au. The orbital inclinations and eccentricities are denoted by $i$ and $e$. $V$ is the velocity before adding the contribution from the acceleration due to the gravitational field of Mars.

\begin{tabular}{|c|c|c|c|c|c|c|}
\hline $\begin{array}{l}\text { comet } \\
\text { name }\end{array}$ & $\begin{array}{l}\text { Period } \\
\text { (y) }\end{array}$ & $\begin{array}{c}q \\
(\mathrm{au})\end{array}$ & $e$ & $\begin{array}{c}i \\
\text { (deg) }\end{array}$ & $\begin{array}{c}V \\
\mathrm{~km} \mathrm{~s}^{-1}\end{array}$ & $\begin{array}{c}V_{i} \\
\mathrm{~km} \mathrm{~s}^{-1}\end{array}$ \\
\hline D/1766 G1 & 4.35 & 0.40603 & 0.84763 & 7.865 & 24.58 & 25.09 \\
\hline $\mathrm{D} / 1819 \mathrm{~W} 1$ & 5.10 & 0.892318 & 0.698752 & 9.1081 & 17.33 & 18.05 \\
\hline P/1994 P1-A & 5.23 & 0.752548 & 0.750145 & 12.7865 & 19.91 & 20.53 \\
\hline $\mathrm{P} / 2000 \mathrm{G} 1 *$ & 5.31 & 1.002858 & 0.670589 & 10.3592 & 15.94 & 16.72 \\
\hline D/1884 O1 & 5.38 & 1.279482 & 0.583252 & 5.4701 & 10.63 & 11.76 \\
\hline D/1886 K1 & 5.44 & 1.325273 & 0.571388 & 12.6710 & 11.47 & 12.52 \\
\hline $\mathrm{D} / 1770 \mathrm{~L} 1$ & 5.60 & 0.674449 & 0.786119 & 1.5517 & 20.74 & 21.35 \\
\hline $\mathrm{D} / 1783 \mathrm{~W} 1$ & 5.89 & 1.459289 & 0.552456 & 45.1277 & 21.74 & 22.32 \\
\hline $\mathrm{D} / 1978 \mathrm{R} 1$ & 5.97 & 1.101411 & 0.665248 & 5.9464 & 14.36 & 15.22 \\
\hline $\mathrm{D} / 1978 \mathrm{C} 2$ & 6.35 & 1.438494 & 0.580362 & 7.0388 & 8.73 & 10.08 \\
\hline $\mathrm{D} / 1892 \mathrm{~T} 1$ & 6.52 & 1.432189 & 0.589631 & 31.2608 & 16.61 & 17.35 \\
\hline P/1999 RO28* & 6.63 & 1.231769 & 0.650817 & 8.1914 & 12.79 & 13.75 \\
\hline $\mathrm{D} / 1896 \mathrm{R} 2$ & 6.65 & 1.454747 & 0.588483 & 11.3507 & 9.47 & 10.72 \\
\hline $\mathrm{P} / 1986 \mathrm{~W} 1$ & 6.75 & 1.457305 & 0.592020 & 1.5285 & 7.87 & 9.34 \\
\hline $\mathrm{P} / 1998 \mathrm{~W} 2 *$ & 6.91 & 1.420189 & 0.608385 & 21.9293 & 13.40 & 14.31 \\
\hline D/1895 Q1 & 7.20 & 1.297763 & 0.652013 & 2.9923 & & 12.44 \\
\hline P/1994 A1 & 7.37 & 1.367310 & 0.638830 & 4.1845 & 10.20 & 11.37 \\
\hline $\mathrm{D} / 1894 \mathrm{~F} 1$ & 7.40 & 1.147000 & 0.697887 & 5.5274 & 14.24 & 15.10 \\
\hline P/1991 V1 & 7.55 & 1.132346 & 0.705642 & 16.8548 & 16.17 & 16.93 \\
\hline D/1984 W1 & 7.84 & 1.319698 & 0.665667 & 21.5677 & 14.87 & 15.70 \\
\hline $\mathrm{P} / 1994$ X1 & 18.2 & 1.276890 & 0.815684 & 29.0741 & 19.06 & 19.71 \\
\hline $\mathrm{P} / 1983$ V1 & 21.5 & 1.282459 & 0.833912 & 95.7312 & 42 & 42.45 \\
\hline P/1991 L3 & 51.3 & 0.982524 & 0.928807 & 19.1904 & 21.35 & 21.94 \\
\hline D/1827 M1 & 57.5 & 0.806508 & 0.945838 & 136.4601 & 50.44 & 50.69 \\
\hline D/1921 H1 & 63.3 & 1.114978 & 0.929088 & 22.3265 & 20.26 & 20.87 \\
\hline D/1989 A3 & 81.9 & 0.420271 & 0.977708 & 83.0672 & 39.95 & 40.26 \\
\hline D/1942 EA & 85.4 & 1.287079 & 0.933639 & 37.9961 & 22.98 & 23.53 \\
\hline $\mathrm{D} / 1917 \mathrm{~F} 1$ & 145 & 0.190186 & 0.993121 & 32.6828 & 35.01 & 35.37 \\
\hline $\mathrm{D} / 1889 \mathrm{M} 1$ & 145 & 1.104 & 0.960033 & 31.2468 & 22.97 & 23.52 \\
\hline D/1984 A1 & 151 & 1.357455 & 0.952214 & 51.8009 & 27.67 & 28.13 \\
\hline C/1999 K4* & 155 & 1.444801 & 0.949944 & 120.9922 & 50.31 & 50.56 \\
\hline D/1937 D1 & 187 & 0.618937 & 0.981098 & 26.0205 & 27.94 & 28.39 \\
\hline $\mathrm{C} / 1905 \mathrm{~F} 1$ & 226 & 1.114641 & 0.969961 & 40.1989 & 25.59 & 26.08 \\
\hline $\mathrm{C} / 1857 \mathrm{O} 1$ & 235 & 0.746843 & 0.980414 & 32.7 & 27.54 & 30.00 \\
\hline $\mathrm{C} / 1855 \mathrm{~L} 1$ & 252 & 0.567564 & 0.985780 & 156.8707 & 51.43 & 51.68 \\
\hline C/1932 Y1 & 262 & 1.130788 & 0.972386 & 24.5025 & 21.05 & 21.64 \\
\hline C/1984 U2 & 270 & 1.214510 & 0.970905 & 13.8812 & 17.57 & 18.27 \\
\hline $\mathrm{C} / 1885 \mathrm{R} 1$ & 275 & 0.749149 & 0.982264 & 59.0970 & 33.69 & 34.07 \\
\hline C/1840 U1 & 286 & 1.479951 & 0.965941 & 57.9043 & 28.59 & 29.03 \\
\hline C/1979 Y1 & 291 & 0.987598 & 0.545164 & 148.6018 & 48.30 & 48.56 \\
\hline $\mathrm{C} / 1932 \mathrm{P} 1$ & 291 & 1.037198 & 0.976369 & 71.7195 & 36.09 & 36.44 \\
\hline C/1932 G1 & 302 & 1.254431 & 0.972127 & 74.2776 & 36.40 & 36.75 \\
\hline C/1941 B1 & 355 & 0.941864 & 0.981221 & 26.2756 & 23.95 & 24.47 \\
\hline C/1955 L1 & 356 & 0.534419 & 0.989361 & 86.5016 & 40.86 & 41.17 \\
\hline $\mathrm{C} / 1931 \mathrm{O} 1$ & 357 & 1.046903 & 0.979203 & 42.2957 & 26.92 & 27.38 \\
\hline C/1964 N1 & 391 & 0.821752 & 0.984643 & 171.9200 & 54.06 & 54.30 \\
\hline C/1979 S1 & 391 & 1.432081 & 0.973197 & 67.0840 & 33.36 & 33.73 \\
\hline C/1861 J1 & 409 & 0.822384 & 0.985070 & 85.4424 & 40.43 & 40.74 \\
\hline C/1861 G1 & 415 & 0.920700 & 0.983465 & 79.7733 & 38.79 & 39.11 \\
\hline $\mathrm{C} / 1898 \mathrm{~F} 1$ & 419 & 1.095261 & 0.980454 & 72.5292 & 36.25 & 36.59 \\
\hline $\mathrm{C} / 1940 \mathrm{O} 1$ & 425 & 1.082228 & 0.980843 & 54.6906 & 30.39 & 30.84 \\
\hline $\mathrm{C} / 1975 \mathrm{~T} 1$ & 446 & 0.838047 & 0.985653 & 118.2332 & 48.03 & 48.30 \\
\hline $\mathrm{C} / 1930 \mathrm{~F} 1$ & 485 & 0.481810 & 0.992194 & 67.1409 & 37.06 & 37.40 \\
\hline C/1843 D1 & 513 & 0.005527 & 0.999914 & 144.3548 & 42.59 & 42.88 \\
\hline
\end{tabular}


Table 2. continued.

\begin{tabular}{ccccccc}
\hline \hline $\mathrm{C} / 1846 \mathrm{~J} 1$ & 538 & 0.633760 & 0.990414 & 150.6809 & 51.55 & 51.79 \\
$\mathrm{C} / 1974 \mathrm{O} 1$ & 551 & 1.372951 & 0.979579 & 173.1585 & 57.25 & 57.47 \\
$\mathrm{C} / 1906 \mathrm{~V} 1$ & 583 & 1.212686 & 0.982624 & 56.3891 & 30.40 & 30.81 \\
$\mathrm{C} / 1998 \mathrm{~K} 5 *$ & 617 & 0.963547 & 0.986701 & 9.9271 & 21.18 & 21.77 \\
$\mathrm{C} / 1952 \mathrm{H} 1$ & 645 & 1.282696 & 0.982816 & 112.0282 & 47.95 & 48.21 \\
$\mathrm{C} / 1882 \mathrm{R} 1 \mathrm{~A}$ & 669 & 0.007750 & 0.999899 & 142.0113 & 42.75 & 43.05 \\
$\mathrm{C} / 1985 \mathrm{~T} 1$ & 700 & 1.317140 & 0.983297 & 139.0692 & 53.73 & 53.97 \\
$\mathrm{C} / 1992 \mathrm{~W} 1$ & 719 & 0.664134 & 0.991721 & 115.1232 & 46.86 & 47.13 \\
$\mathrm{C} / 1987 \mathrm{~B} 2$ & 724 & 0.393020 & 0.995125 & 40.8543 & 33.22 & 33.60 \\
$\mathrm{C} / 1961 \mathrm{~T} 1$ & 759 & 0.681129 & 0.991812 & 155.7107 & 52.32 & 52.56 \\
$\mathrm{C} / 1886 \mathrm{H} 1$ & 768 & 0.269803 & 0.996783 & 87.6615 & 41.33 & 41.63 \\
$\mathrm{C} / 1853 \mathrm{G} 1$ & 781 & 0.908693 & 0.989286 & 122.1955 & 49.11 & 49.37 \\
$\mathrm{C} / 1997 \mathrm{O} 1 *$ & 812 & 1.371801 & 0.984235 & 115.8021 & 49.13 & 49.39 \\
$\mathrm{C} / 1965 \mathrm{~S} 1-\mathrm{A}$ & 880 & 0.007786 & 0.999915 & 141.8642 & 42.77 & 43.07 \\
$\mathrm{C} / 1936 \mathrm{O} 1$ & 888 & 0.518403 & 0.994389 & 121.9417 & 47.38 & 47.64 \\
$\mathrm{C} / 1935 \mathrm{~A} 1$ & 901 & 0.811148 & 0.991304 & 65.4251 & 35.19 & 35.55 \\
$\mathrm{C} / 1963 \mathrm{R} 1$ & 903 & 0.005065 & 0.999946 & 144.5821 & 42.60 & 42.89 \\
$\mathrm{C} / 1963 \mathrm{~A} 1$ & 932 & 0.632139 & 0.993377 & 160.6487 & 52.31 & 52.55 \\
$\mathrm{C} / 1894 \mathrm{G} 1$ & 958 & 0.983032 & 0.989884 & 86.9666 & 40.84 & 41.15 \\
\hline
\end{tabular}

comets in Table 1, namely that the impact velocities of the short-period comets are systematically less than for the longperiod comets. The mean impact velocity of the 37 comets with a period less than 270 years is $14.41 \mathrm{~km} \mathrm{~s}^{-1}$ with the median impact velocity of $20.53 \mathrm{~km} \mathrm{~s}^{-1}$. For all the comets in Table 2, the mean impact velocity is $30.64 \mathrm{~km} \mathrm{~s}^{-1}$ and the median is $30.84 \mathrm{~km} \mathrm{~s}^{-1}$.

Figure 2 shows two histograms of the number of comets as a function of impact velocity. The upper one is for the 37 comets with $P \leq 270$ y in Table 2 and the lower histogram is for remaining 38 comets in Table 2 . The velocity distribution in the upper histogram is similar to the histogram for all the numbered comets shown in Fig. 1, with most of the calculated impact velocities lying in the range between 10 and $25 \mathrm{~km} \mathrm{~s}^{-1}$. For the 38 comets shown in the lower histogram, the impact velocities are all larger than $20 \mathrm{~km} \mathrm{~s}^{-1}$ and most in fact lie between 30 and $55 \mathrm{~km} \mathrm{~s}^{-1}$.

Looking in more detail at Tables 1 and 2, we find the high impact speed is associated with high orbital inclination. The reason for this is easy to see from Eq. (3). There is one term in the equation $\left(2\left(\frac{q(1+e)}{r_{\mathrm{m}}}\right)^{0.5} \cos i\right)$ that is large and negative for small values of $i$, but decreases with increasing $i$ and becomes positive when $i>\pi / 2$. Most short period comets have low inclinations and long period comets generally have high inclinations. Hence, though there is no direct connection between period and impact velocity, it is still true that a high impact velocity will only arise from long period comets.

\section{Meteor shower on Mars}

Meteors are the visible effects produced by the ablation of a meteoroid following its impact with the upper atmosphere. Meteor showers are the consequence of the Earth intersecting a stream of meteoroids and we have already outlined the connection between meteoroid streams and comets. The height in the atmosphere at which meteoroid ablate depends on the atmospheric density and the impact velocity. If we accept the conclusions of Hughes \& Williams (2000) that the impact velocity of comets and meteoroids are similar and also compare their velocity distribution with ours as found above, we conclude that meteoroids will impact Mars with a slightly lower velocity than with the Earth. The atmosphere of Mars is thinner than that of the earth, but does not decay as rapidly and, perhaps by coincidence, the two effects essentially cancel each other so that, according to Adolfsson et al. (1996), meteoroids will ablate on Mars at a height of about $120 \mathrm{~km}$, essentially the same height as where ablation takes place on Earth. Hence, meteor showers should be visible on Mars just as on Earth. The brightness of a meteor is related to the impact velocity as well as meteoroid radius and density. Hughes (1978), Hughes \& Williams (2000) gives the magnitude of a meteor as

$M=A-B \log m-C \log V_{i}$

where $M$ is the zenithal visual magnitude of the meteor, $m(\mathrm{~g})$ is the mass of the causative meteoroid and $V_{i}\left(\mathrm{~km} \mathrm{~s}^{-1}\right)$ is the impact velocity of the meteoroid with the atmosphere. $A, B$ and $C$ are constants which are dependent on the model of atmosphere.

Hence, we should expect the magnitude of a meteor on Mars to be larger (ie the meteor fainter) than a meteor caused by an identical meteoroid on Earth. Hence, we should expect to see fewer visible meteors as the many faint meteors seen on Earth would not be observable on Mars. Adolfsson et al. (1996) has investigated this in some detail and showed that meteoroids with speed ( $\geq 30 \mathrm{~km} \mathrm{~s}^{-1}$ ) would produce meteors of similar brightness in the atmospheres of both Earth and Mars; lower speed meteoroids would however be fainter in Martian atmosphere.

In Tables 1 and 2, there are 12 comets among the comets with period $<200$ year that have a calculated impact speed with Mars $\geq 30 \mathrm{~km} \mathrm{~s}^{-1}$. Of course, many of the comets with longer periods also have a large impact velocities with Mars, but long period comets are not generally associated with known meteoroid stream at Earth, probably because the time interval over 

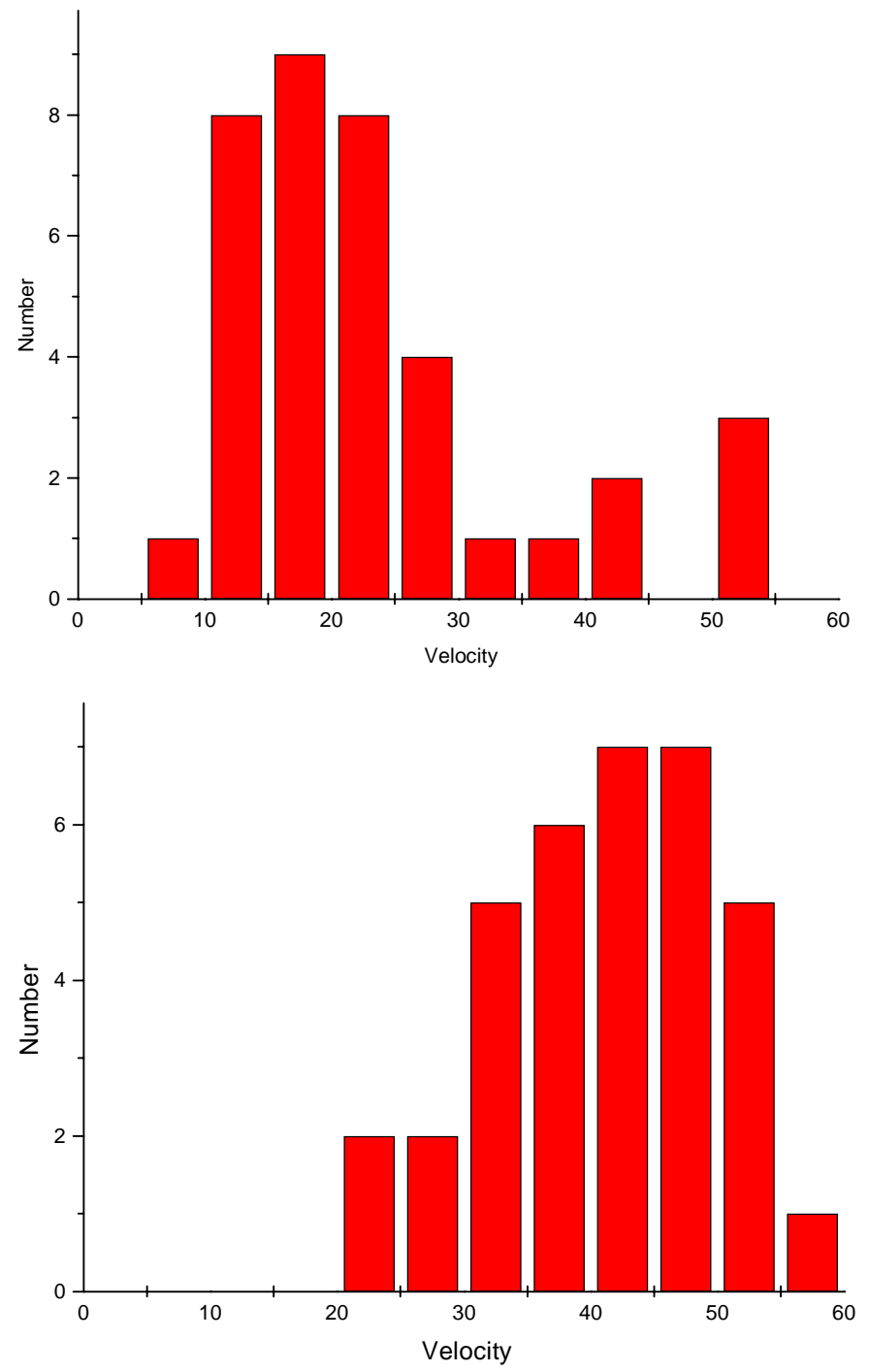

Fig. 2. These histograms show the distribution of impact velocities of the unnumbered periodic comets given in Marsden \& Williams (1996) that have $q<1.52 \mathrm{au}$. The upper is for 37 comets with orbital period $P \leq 270 \mathrm{y}$, and the lower for the remaining 38 comets with $270<P<$ $960 \mathrm{y}$.

which the comet is active and so producing meteoroids is very short compared to the orbital period. Any potential stream dissipates long before the meteoroids can spread along the orbit.

We also note that in producing the results reported in Tables 1 and 2, the argument of perihelion was artificially adjusted so as to force the orbit to cross the ecliptic at $1.52 \mathrm{au}$. Many of these cometary orbits do not in reality pass close to Mars. Hence, it is incorrect to imagine that all the comets listed will produce a visible meteor shower on Mars if the impact velocity is in the correct range of values. Using the real orbits, Christou \& Beurle (1999) identified only 1P/Halley and $13 \mathrm{P} /$ Olbers as comets that potentially likely to generate bright meteors on Mars. Treiman \& Treiman (2000) suggested that 45P/Honda-Mrkos-Pajdusakova should be added to this list of comets that can produce bright Martian meteors.

However, we must also remember that in order to cause many of the potential catastrophes mentioned in the introduction, the meteor does not need to be bright. Many more comets pass close to the Martian orbit than pass close to Earth's orbit. Of the periodic Mars-crossing comets, 56 approach Mars' orbit within 0.15 au (Treiman \& Treiman 2000). This suggests that Mars may experience many more faint meteor showers than Earth. These can be detected by radio and in future missions to Mars, a radio detector should be included on the payload so that the risk of damage to equipment in the Martian environment can be properly assessed.

Acknowledgements. We are gratefully to acknowledge M. Fulle for his suggestions and comments which helped to improve this paper. Yuehua Ma would like to acknowledge the support of the National Natural Science Foundation of China (No. 19873020), National Science Council of Taiwan (NSC-90-2816-M-008-0002-6), the Minor Planetary Foundation of Purple Mountain Observatory and the Scientific Research Funding for the Returned Overseas Chinese Scholars, State Personnel Ministry. Yuehua Ma and Wenping Chen would like to acknowledge the support of the grant NSC90-2112-M008-021.

\section{References}

Adolfsson, L. G., Gustafson, B. A. S., \& Murray, C. D. 1996, Icarus, 119,144

Babadzhanov, P. B., \& Obrubov, Yu. V. 1992, Celest. Mech. Dyn. Astron., 54, 111

Beech, M., Brown, P., \& Jones, J. 1995, Q. J. R. Astron. Soc., 36, 127

Beech, M. Brown, P., Jones, J., \& Webster, A. R. 1997, Adv. Space Res., 20, 1509

Caswell, R. D., McBride, N., \& Taylor, A. D. 1995, Int. J. Impact Eng., 17, 139

Christou, A. A., \& Beurle, K. 1999, Planet. Space Sci., 47, 1475

Hughes, D. W. 1978, in Cosmic Dust, ed. J. A. M. McDonnell (John Wiley \& Sons, Chichester), 123

Hughes, D. W., \& Williams, I. P. 2000, MNRAS, 315, 629

Kirkwood, D. 1861, Danville Quart. Rev., 1, 614

Marsden, B. G., \& Williams, G. V. 1996, Catalogue of Cometary Orbits 1996 (International Astronomical Union)

McBride, N. 1997, Adv. Space Res., 20, 1513

McBride, N., \& McDonnell, J. A. M. 1999, Planet. Space Sci., 47, 1005

Steel, D. 1994, in Asteroids Comets Meteors 1993, ed. A. Milani, M. di Martino, \& A. Cellino (Kluwer Acad. Publ., Dordrecht)

Treiman, A. H., \& Treiman, J. S. 2000, J. Geophys. Res., 105, 24571

Whipple, F. L. 1951, ApJ, 113, 464

Williams, I. P. 1996, in Physics, Chemistry and Dynamics of Interplanetary Dust. Astron. Soc. Pac., ed. B. Å. S. Gustafson, \& M. S. Hanner, ASP Conf. Ser., 104 (San Francisco) 